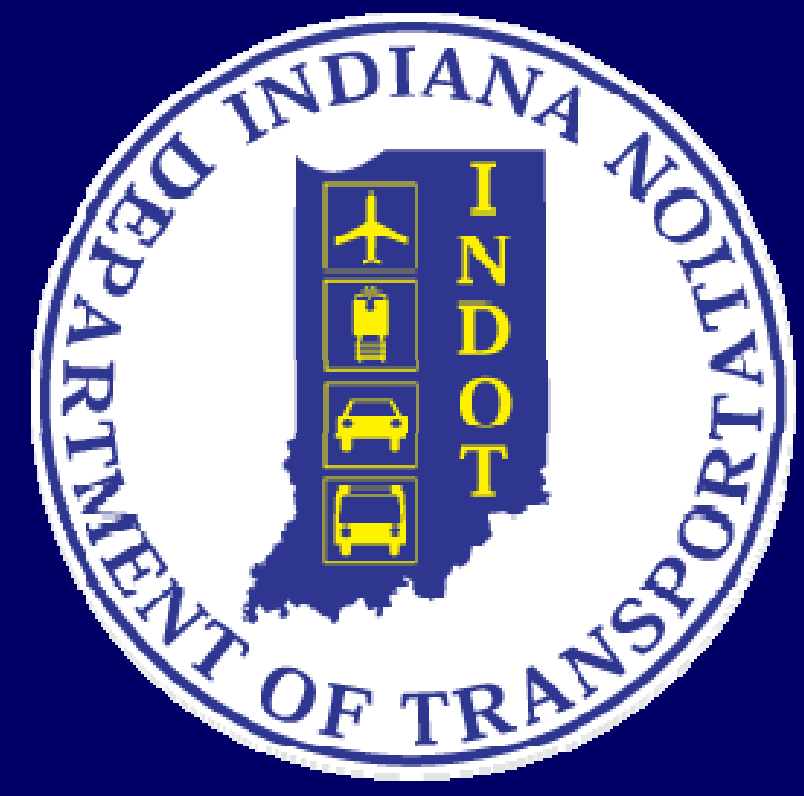

Driving Indiana's Economic Growth 
Michelle Allen

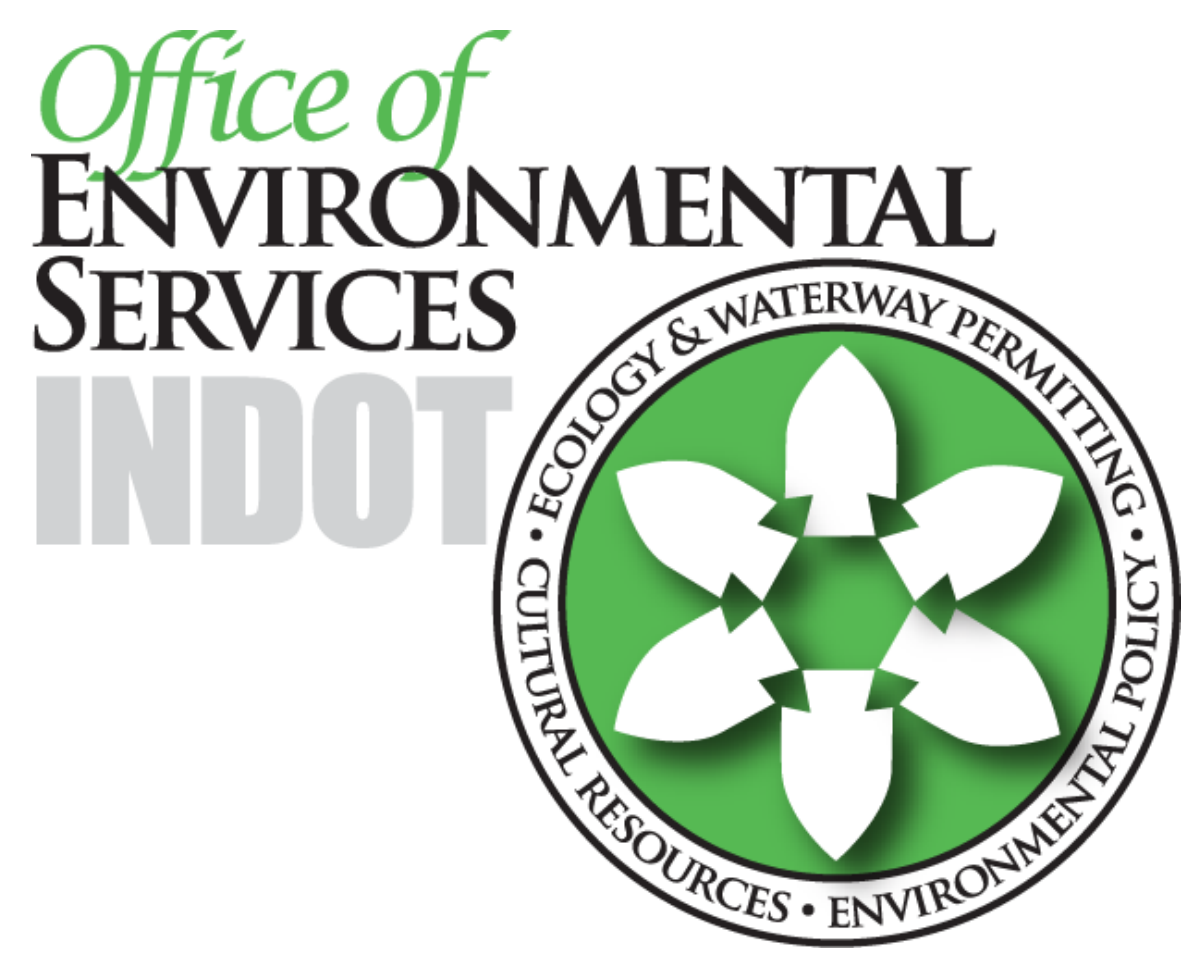

Manager, INDOT Office of Environmental Services

Nathan Saxe

Administrator, Ecology and Waterway Permitting Section, OES 


\section{Erosion and Sediment Control}

- Erosion and Sediment Control (E\&SC)

- Rule 5: What is it

- 327 IAC 15-5-1 The purpose of this rule is to establish requirements for storm water discharges from construction activities of one (1) acre or more so that the public health, existing water uses, and aquatic biota are protected.

- Sediment/Pollution runoff from project site 


\section{Erosion and Sediment Control}

- Who Regulates Rule 5

- Indiana Dept. of Environmental

Management (IDEM)

- Where is I NDOT's Past Compliance?

- INDOT Compliance Data

- Indiana Department of Environmental Management (IDEM) or the local Soil and Water Conservation Districts (SWCDs) Inspection Reports

- July 2006 to October 2009

- Analyzed for compliance

- Overall Rating of Satisfactory, Marginal and Unsatisfactory 


\section{Figure 1: Erosion and Sediment Control Inspection Report Results}

\section{July 2006-October 2009 Inspections}

Report Prepared 11/3/09

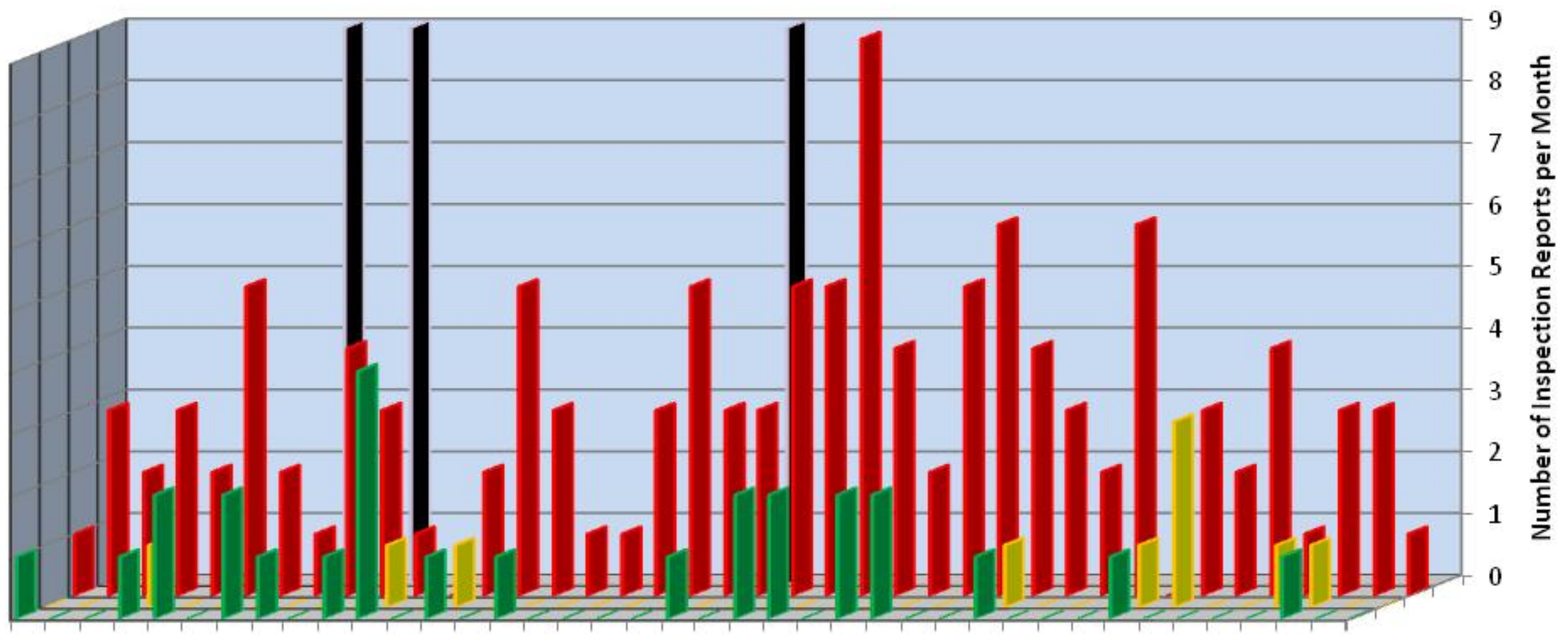

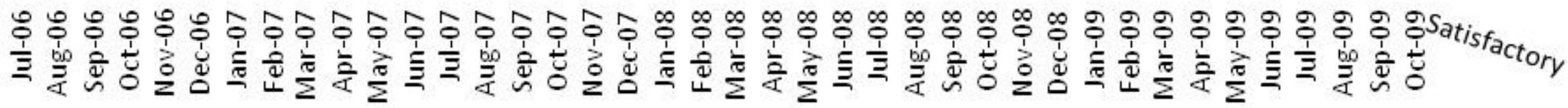
Month 


\section{I nspection Report Results}

- Of the inspection reports received between / uly 2006 and October 2009:

- 155 inspection reports received

- 62 contracts received inspection reports

- $83.2 \%$ of all reports were either unsatisfactory or marginal

- IDEM I nspections Complaint driven and not consistent across the State and INDOT Districts 


\section{I nspection Report Results}

- Of the inspection reports received between / uly 2006 and October 2009: (cont.)

- Repeat I nspection Reports

- Avg. 2.5 inspection reports/contract

- 60\% rec'd on previously inspected contracts

- 79.0\% unsatisfactory or marginal First Notice

- 86.2\% unsat. or marg. Repeat Inspections 


\section{NDOT Statewide Compliance}

- Largest Observed Violators

- Typically Larger Projects

- New Alignment/Added Travel Lanes

- (large grading = lots of exposed soil)

- Overwintering Projects

- Exposed Soils not stabilized prior to end of growing season

- Projects with Dewatering

- Dewatering methods typically aren't adequate

- Projects with Work in Waterway

- Bridges/structures 


\section{NDOT Contract I tems Results}

- Of the INDOT Contracts Active from /anuary 1, 2007 to September 1, 2009:

- 493 Contracts let with E\&SC items $(\$ 1,932,601,471)$

- $0.46 \%(\$ 8,889,966)$ of budget Temporary E\&SC items including change orders

- $0.14 \%(\$ 2,705,642)$ of budget Temp. E\&SC items dispersed

- $70 \%$ (roughly $\$ 6$ million) of E\&SC Item dollars in the contracts were not paid for on I NDOT contracts 


\section{NDOT Rule 5 Compliance}

- Conclusions:

- INDOT must acknowledge that a majority of our contracts are out of compliance with Rule 5 E\&SC.

- Despite previous notification of a lack of compliance, INDOT staff and its contractors are not responsive to the violation notices resulting in repeat inspections, repeat violations and potential IDEM and EPA enforcement. (Do the plans include measures necessary to be responsive?)

- The lack of implementation of $\$ 6$ million worth of E\&SC items that are in the contracts must be further investigated and likely contributes to the lack of compliance. (Thoughtful Design?)

- The risk of non-compliance is too great for current INDOT projects to delay participation in changing current INDOT practices. 


\section{NDOT Changes - Design}

- J oint Transportation Research Program (JTRP)

- Addresses Research Needs for INDOT

- INDOT's need for E\&SC research

- Current State of Compliance

- SPR - 2853

- "Assessment and Selection of Stormwater Best Management Practices (BMPs) for Highway Construction, Retrofitting and Maintenance"

- Published October 2006

- Wasn't implemented (Reorganization) 


\section{NDOT Changes - Design}

\section{J oint Transportation Research Program}

- INDOT's need for E\&SC research

- Indiana Stormwater Quality Manual (Oct. ‘07)

- http://www.in.gov/idem/4899.htm 


\section{NDOT Changes - Design}

- JTRP SPR - 3312

- I dentification and Implementation of Best Management Practices (BMPS) for E\&SC that Conform to the Indiana Storm Water Quality Regulations and Guidance

- Lead I nvestigator - Dr. Lynn Corson

- Study Advisory Committee Members

- I NDOT Project Management, Design, Construction, Maintenance Staff

- Consultants, Contractors, IDEM 


\section{NDOT Changes - Design}

- JTRP SPR - 3312

- Goals

1. Update the BMP list, descriptions and matrix according to IDEM Manual

2. Review the recommendations in SPR-2853 and recommend changes to the Standards Committee

3. Revise and re-submit INDOT'S NPDES Stormwater permit application to IDEM 


\section{INDOT Changes - Design}

- JTRP SPR - 3312

- Goals

4. Develop, adapt or adopt an E\&SC training curriculum

5. Prepare a field manual of BMPs and standards 


\section{What's Coming?}

- Task Force Recommendations

- Monetary Damages for Contractor

- Training

- E\&SC Specialist at each District

- Demonstration Projects

- Design Build E\&SC

- Rapid Stabilization Areas 
- New EPA Regulations

- Will require monitoring of runoff from construction sites

- IDEM will be determining how regulations will be implemented in Indiana

- Expect new guidelines within the next year or two. 


\section{Questions?}

Michelle Allen - mballen@indot.I N.gov 317-232-5135

Nathan Saxe - nsaxe@indot.I N.gov 317-232-0240

Rick Phillabaum - rphillabaum@indot. I N.gov 317-233-5151 